\title{
-Original-
}

\section{Diagnosis of Vertebral Artery Dissection with Basiparallel Anatomical Scanning Magnetic Resonance Imaging}

\author{
Makoto Katsuno $^{1}$ and Shiro Kobayashi ${ }^{2}$ \\ ${ }^{1}$ Abashiri Neurosurgical Rehabilitation Hospital, Hokkaido \\ ${ }^{2}$ Department of Neurosurgery, Nippon Medical School Chiba Hokuso Hospital
}

\begin{abstract}
Background and Purpose: There is no consensus regarding the optimal method for diagnosing the dissection of intracranial arteries. We have developed a rapid and accurate examination method to diagnose vertebral artery dissection in the acute stage of cerebral infarction.

Methods: Twenty-two patients with severe headache and neck pain and/or symptoms of brain stem or cerebellar ischemia underwent magnetic resonance imaging (MRI) with a 1.5-T scanner. Our protocol generated 3 contrast-weighted scans (T2-weighted, diffusion-weighted, and basi-parallel anatomical scanning (BPAS]-MRI) and conventional angiographs within 3 hours of the onset of symptoms. Then, we retrospectively analyzed the findings to identify the most reliable imaging method for diagnosing vertebral artery dissection in the acute stage of cerebral infarction.

Results: Based on the symptoms and the findings of T2-weighted imaging and conventional angiography, the initial diagnosis was dissection in 17 patients, lacunar infarction in 3 patients, and atherothrombosis in 2 patients. After follow-up studies the diagnosis was changed in 7 patients. The diagnosis based on symptoms and the findings of T2-weighted MRI and BPAS-MRI was dissection in 13 patients, atherothrombosis in 6 patients, and lacunar infarction in 3 patients. In 3 patients the diagnosis was changed during the follow-up phase.

Conclusions: The diagnostic accuracy rate was higher with T2-weighted MRI and BPASMRI than with T2-weighted MRI and conventional angiography. We suggest that when intracranial vascular dissection is suspected, both the inner and outer contours of vessels must be inspected and that BPAS-MRI should be performed instead of conventional angiography to establish the definite diagnosis.
\end{abstract}

(J Nippon Med Sch 2011; 78: 367-373)

Key words: dissection, diagnosis, magnetic resonance imaging, angiography, vertebral artery

\section{Introduction}

Patients in the hyper-acute stage of cerebral infarction usually receive thrombolytic therapy. Because some patients with cerebral infarction also have intracranial vertebral artery dissection, their treatment remains controversial. Because dissection

Correspondence to Makoto Katsuno, MD, Abashiri Neurosurgical Rahabilitation Hospital, 4-1-7 Katsuramachi,

Abashiri, Hokkaido 093-0041, Japan

E-mail: mkatsuno@nms.ac.jp

Journal Website (http://www.nms.ac.jp/jnms/) 
of the intracranial vertebral artery may lead to subarachnoid hemorrhage during anticoagulation therapy for cerebral infarction ${ }^{1}$, a rapid and accurate diagnosis is important for appropriate management. However, there is no consensus regarding the optimal method for diagnosing intracranial dissection. Conventional angiography has been considered the standard means of diagnosis ${ }^{2.3}$, but carries a risk of complications and does not provide information on the condition of the arterial wall. Therefore, rapid, noninvasive diagnostic techniques, e.g., magnetic resonance imaging (MRI) and MR angiography (MRA), have been developed.

The MRI findings suggestive of arterial dissection $^{4-8}$ include arterial intramural hematoma on T1-weighted images, intimal flap on T2-weighted images, and double lumen and enhancement of the wall and septum on contrast-enhanced 3-dimensional (3-D) spoiled gradient-recalled acquisition images ${ }^{4}$. According to Nagahata et al. ${ }^{9}$, basiparallel anatomical scanning MRI (BPAS-MRI) provides useful information on vertebrobasilar vascular lesions, especially in patients with arterial dissection.

Diffusion-weighted imaging (DWI) is sensitive to the diffusion of water molecules and is commonly used as the initial imaging examination for detecting acute cerebral infarction. In the present study, patients in the acute stage of vertebrobasilar vascular disease underwent DWI MRI, T2-weighted MRI, BPAS-MRI, and conventional angiography to identify the fastest and most accurate method for diagnosing vertebral artery dissection.

\section{Materials and Methods}

Our study population comprised 22 patients (17 men, 5 women; age range 36 to 76 years; mean age 56.4 years) who presented with severe headache and neck pain and/or symptoms of a disturbance of the posterior circulation, such as dysphagia, ataxia, diplopia, and dizziness. Within 3 hours after the onset of symptoms, all patients underwent conventional angiography and MRI examinations that generated 3 contrast-weighted images (T2, diffusion, BPAS). Because some reports have described the MRA as being insufficient for screening for intracranial vertebrobasilar artery dissection $^{4}$, we did not perform MRA.

All MRI examinations were performed with a 1.5$\mathrm{T}$ scanner (SIGNA Infinity EXCITE XL 1.5T, GE Medical Systems, Milwaukee, WI, USA) using axial turbo spin-echo T2-weighted imaging and axial gradient-echo imaging. The imaging parameters were 4,800/100 (TR/TE) for $\mathrm{T} 2$ and 700/23 for gradient-echo imaging, a 200- to $220-\mathrm{mm}$ field of view, a $256 \times 256$ matrix, and $3-\mathrm{mm}$ section thickness. BPAS-MRI was performed in a $20-\mathrm{mm}$ thick coronal section parallel to the clivus using a fast spin-echo sequence. The imaging parameters were 10,000/400 (TR/TE), a 220- × 220-mm FOV, and a $512 \times 256$ matrix. With this pulse sequence, the total acquisition time was 4 minutes 28 seconds.

Conventional angiography was performed with digital subtraction 1 to 2 hours after the MRI scans. The diagnosis of dissection, fusiform aneurysm, or atherosclerotic change at the site of vertebrobasilar vascular lesions was based on the clinical history and the findings of conventional angiography and MRI. We suspected dissection when there was evidence of intra-arterial lesions, such as mural hematoma, intimal flap, double lumen, and plaque on T2-weighted MRI; intimal flap, double lumen, the pearl sign, the string sign, stenosis, dilatation, and tapered occlusion on angiographs; and dilatation or irregularity on BPAS images. We studied these patients on admission and diagnosed dissection if MRI findings changed during the follow-up phase; for example, if there was a change in the intensity of intra-arterial lesions on T1- or T2-weighted MRI or a change on BPAS-MRI scans. However, we suspected atherothrombosis if the initial BPAS image showed no abnormal findings, even when other examination demonstrated abnormal findings.

\section{Results}

The final diagnosis was intracranial vertebrobasilar artery dissection in 14 patients, atherothrombotic infarction in 4 patients, and lacunar infarction in 3 patients; 1 patient had a true aneurysm (Table 1, 2).

The initial symptoms were headache alone in 4 
Table 1 Summary of clinical and initial neuroradiological findings in 22 patients

\begin{tabular}{|c|c|c|c|c|c|c|c|}
\hline Case & Age/Sex & Symptoms & $\begin{array}{l}\text { High intensity } \\
\text { area of DWI }\end{array}$ & $\begin{array}{c}\text { Site of } \\
\text { abnormal } \\
\text { vessel }\end{array}$ & $\begin{array}{c}\text { T2WI } \\
\text { (intensity) }\end{array}$ & BPAS & Angiography \\
\hline 1 & $36 / F$ & $\begin{array}{c}\text { HA, } \\
\text { Dysphagia }\end{array}$ & $\begin{array}{l}\text { Lateral } \\
\text { medullary }\end{array}$ & VA & NP & Dilatation & Pearl\&String \\
\hline 2 & $63 / \mathrm{M}$ & $\begin{array}{c}\text { HA, Gait } \\
\text { disturbance }\end{array}$ & none & VA & $\begin{array}{c}\text { Plaque or Mural } \\
\text { Hx (iso) }\end{array}$ & Dilatation & Dilatation \\
\hline 3 & $62 / \mathrm{M}$ & HA & none & VA & $\begin{array}{c}\text { Plaque or Mural } \\
\text { Hx (iso) }\end{array}$ & Dilatation & Intimal flap \\
\hline 4 & $68 / \mathrm{M}$ & $\begin{array}{c}\text { HA, Gait } \\
\text { disturbance }\end{array}$ & $\begin{array}{l}\text { Lateral } \\
\text { medullary }\end{array}$ & VA & $\begin{array}{c}\text { Plaque or Mural } \\
\text { Hx (iso) }\end{array}$ & NP & String \\
\hline 5 & $41 / \mathrm{F}$ & Dysphagia & $\begin{array}{l}\text { Medial } \\
\text { medullary }\end{array}$ & NP & $\mathrm{NP}$ & NP & NP \\
\hline 6 & $71 / \mathrm{M}$ & Tetraplegia & none & $\mathrm{BA}$ & $\begin{array}{l}\text { Plaque or Mural } \\
\text { Hx (high) }\end{array}$ & Dilatation & Dilatation \\
\hline 7 & $55 / \mathrm{M}$ & $\begin{array}{c}\text { HA, } \\
\text { Dysphagia }\end{array}$ & $\begin{array}{l}\text { Lateral } \\
\text { medullary }\end{array}$ & VA & $\begin{array}{l}\text { Plaque or Mural } \\
\text { Hx (low) }\end{array}$ & Irregularity & Occlusion \\
\hline 8 & $67 / \mathrm{M}$ & Hoarseness & none & VA & $\mathrm{NP}$ & Dilatation & Dilatation \\
\hline 9 & $48 / \mathrm{M}$ & $\begin{array}{c}\text { HA, Gait } \\
\text { disturbance }\end{array}$ & $\begin{array}{l}\text { Cerebellar } \\
\text { hemisphere }\end{array}$ & VA & NP & NP & NP \\
\hline 10 & $55 / \mathrm{M}$ & HA & none & VA & $\begin{array}{c}\text { Plaque or Mural } \\
\text { Hx (iso) }\end{array}$ & Dilatation & Dilatation \\
\hline 11 & $48 / \mathrm{M}$ & $\begin{array}{c}\text { HA, } \\
\text { Dizziness }\end{array}$ & $\begin{array}{l}\text { Lateral } \\
\text { medullary }\end{array}$ & VA & Double lumen & Dilatation & Intimal flap \\
\hline 12 & $69 / \mathrm{M}$ & $\begin{array}{l}\text { HA, Double } \\
\text { vision }\end{array}$ & none & VA & $\begin{array}{c}\text { Plaque or Mural } \\
\text { Hx (mix) }\end{array}$ & Dilatation & Occlusion \\
\hline 13 & $54 / \mathrm{M}$ & $\begin{array}{c}\text { HA, } \\
\text { Dysphagia }\end{array}$ & Pons & $\mathrm{BA}$ & Intimal flap & Dilatation & Stenosis \\
\hline 14 & $71 / \mathrm{M}$ & HA & none & VA & NP & Dilatation & Dilatation \\
\hline 15 & $76 / \mathrm{M}$ & $\begin{array}{l}\text { Double } \\
\text { vision }\end{array}$ & $\begin{array}{l}\text { Lateral } \\
\text { medullary }\end{array}$ & NP & NP & NP & NP \\
\hline 16 & $53 / \mathrm{M}$ & $\begin{array}{c}\text { Gait } \\
\text { disturbance }\end{array}$ & $\begin{array}{l}\text { Cerebellar } \\
\text { hemisphere }\end{array}$ & VA & $\begin{array}{c}\text { Plaque or Mural } \\
\text { Hx (low) }\end{array}$ & NP & Occlusion \\
\hline 17 & $72 / \mathrm{F}$ & $\begin{array}{l}\text { HA, Double } \\
\text { vision }\end{array}$ & $\begin{array}{c}\text { Cerebellar } \\
\text { hemisphere }\end{array}$ & VA & $\begin{array}{c}\text { Plaque or Mural } \\
\text { Hx (high) }\end{array}$ & NP & NP \\
\hline 18 & $62 / \mathrm{M}$ & $\begin{array}{c}\text { Gait } \\
\text { disturbance }\end{array}$ & $\begin{array}{l}\text { Cerebellar } \\
\text { hemisphere }\end{array}$ & $\mathrm{BA}$ & $\begin{array}{c}\text { Plaque or Mural } \\
\text { Hx (iso) }\end{array}$ & NP & String \\
\hline 19 & $45 / \mathrm{F}$ & HA & none & VA & Intimal flap & Dilatation & $\begin{array}{l}\text { Double } \\
\text { lumen }\end{array}$ \\
\hline 20 & $63 / \mathrm{M}$ & $\begin{array}{c}\text { Gait } \\
\text { diturbance }\end{array}$ & $\begin{array}{l}\text { Cerebellar } \\
\text { hemisphere }\end{array}$ & VA & $\begin{array}{c}\text { Plaque or Mural } \\
\text { Hx (iso) }\end{array}$ & NP & Stenosis \\
\hline 21 & $46 / \mathrm{F}$ & $\begin{array}{c}\text { HA, } \\
\text { Dysarthria }\end{array}$ & $\begin{array}{l}\text { Cerebellar } \\
\text { vermis }\end{array}$ & VA & $\begin{array}{c}\text { Plaque or Mural } \\
\text { Hx (high) }\end{array}$ & Irregularity & Dilatation \\
\hline 22 & $53 / \mathrm{M}$ & $\begin{array}{c}\text { Gait } \\
\text { disturbance }\end{array}$ & $\begin{array}{c}\text { Cerebellar } \\
\text { hemisphere }\end{array}$ & NP & $\mathrm{NP}$ & NP & NP \\
\hline
\end{tabular}

Abbreviations: DWI, diffusion-weighted image; T2WI, T2-weighted image; BPAS, basiparallel anatomical scanning; F, female; M, male; HA, headache; VA, vertebral artery; BA, basilar artery; Mural Hx, mural hematoma; NP, no particular finding.

patients, symptoms of posterior circulation disturbance alone in 8 patients, and both in 10 patients. Among the 14 patients with dissection, 4 complained of headache and neck pain but had no symptoms of posterior circulation disturbance; only 1 patient had quadriplegia without headache. In 14 patients DWI confirmed cerebral infarction: at the cerebellar hemisphere in 6 patients; at the lateral medulla in 5 patients; and at the medial medulla, cerebellar vermis, and pons in 1 patient each. Three of the 5 patients with a diagnosis of dissection had a cerebral infarction at the lateral medulla. Fifteen patients showed anomalous intra-arterial findings raising the possibility of dissection on T2-weighted MRI: mural hematoma or plaque in 12 patients, intimal flap in 2 patients, and double lumen in 1 
Table 2 Difference between initial and final diagnoses in 22 patients

\begin{tabular}{rccc}
\hline Case & $\begin{array}{c}\text { Initial diagnosis from } \\
\text { T2WI and AG findings }\end{array}$ & $\begin{array}{c}\text { Initial diagnosis } \\
\text { from T2WI and } \\
\text { BPAS findings }\end{array}$ & $\begin{array}{c}\text { Final diagnosis } \\
\text { from follow up } \\
\text { examinations }\end{array}$ \\
\hline 1 & Dissection & Dissection & Dissection \\
2 & Dissection & Dissection & Dissection \\
3 & Dissection & Dissection & Dissection \\
4 & Dissection & Atherothrombosis & Atherothrombosis \\
5 & Lacunar infarction & Lacunar infarction & Lacunar infarction \\
6 & Dissection & Dissection & Dissection \\
7 & Dissection & Dissection & Dissection \\
8 & Dissection & Dissection & True aneurysm \\
9 & Athreothrombosis & Atherothrombosis & Dissection \\
10 & Dissection & Dissection & Dissection \\
11 & Dissection & Dissection & Dissection \\
12 & Dissection & Dissection & Dissection \\
13 & Dissection & Dissection & Dissection \\
14 & Dissection & Dissection & Dissection \\
15 & Lacunar infarction & Lacunar infarction & Lacunar infarction \\
16 & Dissection & Atherothrombosis & Atherothrombosis \\
17 & Atherothrombosis & Atherothrombosis & Dissection \\
18 & Dissection & Atherothrombosis & Atherothrombosis \\
19 & Dissection & Dissection & Dissection \\
20 & Dissection & Atherothrombosis & Atherothrombosis \\
21 & Dissection & Dissection & Dissection \\
22 & Lacunar infarction & Lacunar infarction & Lacunar infarction \\
\hline
\end{tabular}

Abbreviations: T2WI, T2-weighted image; AG, angiography; BPAS, basiparallel anatomical scanning.

patient.

Abnormal angiographic findings were noted in 17 patients: vascular dilatation in 6 patients; tapering occlusion in 3 patients; intimal flap, the string sign, and stenosis in 2 patients each; and the pearl-andstring sign and double lumen in 1 patient each. The sensitivity and specificity of angiography were $86.7 \%$ and $42.9 \%$, respectively. BPAS-MRI showed abnormalities in 13 patients: dilatation in 11 patients and irregularities in 2 patients. The sensitivity and specificity of BPAS-MRI were $84.6 \%$ and $77.8 \%$, respectively.

On the basis of symptoms and the findings of $\mathrm{T} 2$ weighted MRI and conventional angiography, dissection was initially diagnosed in 17 patients, lacunar infarction in 3 patients, and atherothrombosis in 2 patients. After the follow-up study, the diagnosis was changed in 7 patients: from dissection to atherothrombosis in 4 patients, from atherothrombosis to dissection in 2 and from dissection to true aneurysm in 1 patient. The sensitivity and specificity of the combination of T2weighted MRI and convetional angiography were $85.7 \%$ and $37.5 \%$, respectively. On the other hand, on the basis of symptoms and the findings of T2weighted MRI, and BPAS-MRI, dissection was initially diagnosed in 13 patients (Fig. 1, case 3), atherothrombosis in 6 patients, and lacunar infarction in 3 patients. In the chronic stage, the diagnosis was changed in 3 patients: from atherothrombosis to dissection in 2 and from dissection to true aneurysm in 1 patient (Fig. 2, case 4; Fig. 3, case 17). The sensitivity and specificity of the combination of T2-weighted MRI and BPAS-MRI were $85.7 \%$ and $87.5 \%$, respectively.

The diagnostic accuracy of the combination of T2weighted MRI and BPAS-MRI was greater than that of the combination of T2-weighted MRI and angiography. 

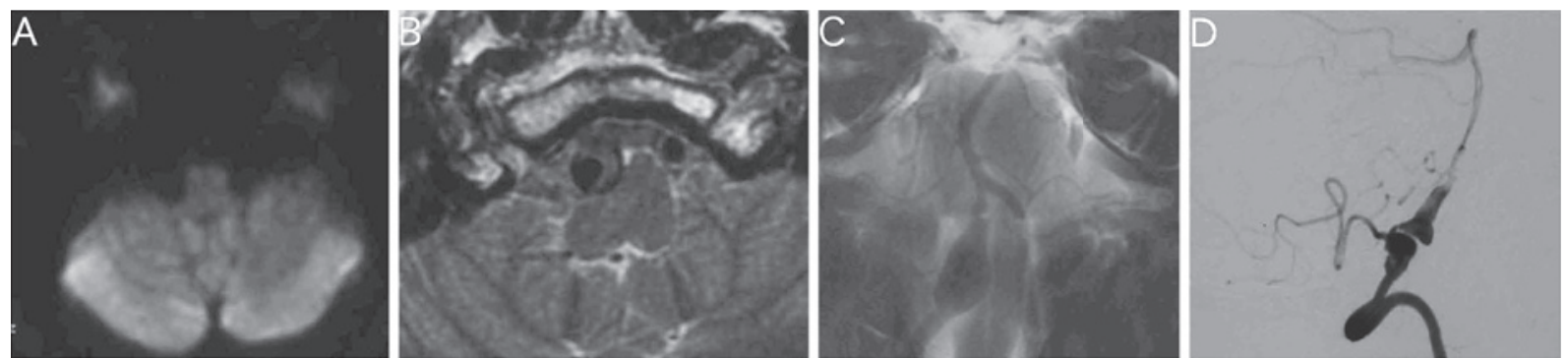

Fig. 1 Case 3. A 62-year-old man complaining of headache. Both the initial diagnosis based on the findings of T2weighted imaging and angiography and on the findings of T2-weighted imaging and basiparallel anatomical scanning (BPAS), and the final diagnosis was dissection. (A) No abnormal findings were detected on diffusionweighted image. (B) T2-weighted imaging revealed a mural hematoma in the right vertebral artery. (C) BPAS showed dilatation of the right vertebral artery. (D) Right vertebral angiography (lateral view) demonstrating an intimal flap in a fusiform aneurysm.
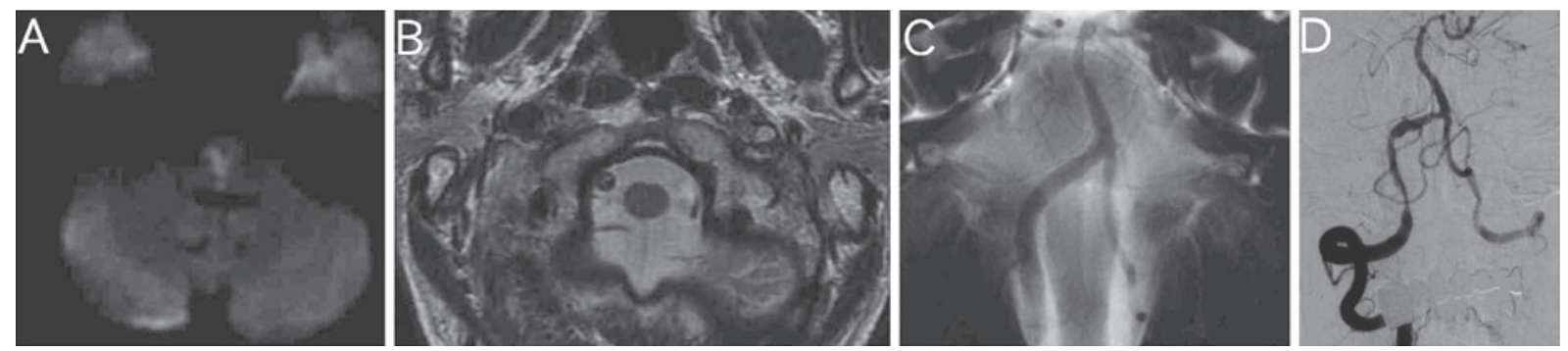

Fig. 2 Case 4. A 68-year-old man admitted for headache and gait disturbance. Although the initial diagnosis based on the findings of T2-weighted imaging and angiography, was dissection, both the initial diagnosis and final diagnosis, based on the findings of T2-weighted imaging and basiparallel anatomical scanning (BPAS) was atherothrombosis. (A) Acute cerebral infarction at the right lateral medulla was observed on the diffusionweighted imaging. (B) A mural hematoma was demonstrated in the right vertebral artery. (C) The shape of right vertebral artery was normal on BPAS. (D) Right vertebral artery demonstrating the string sign.
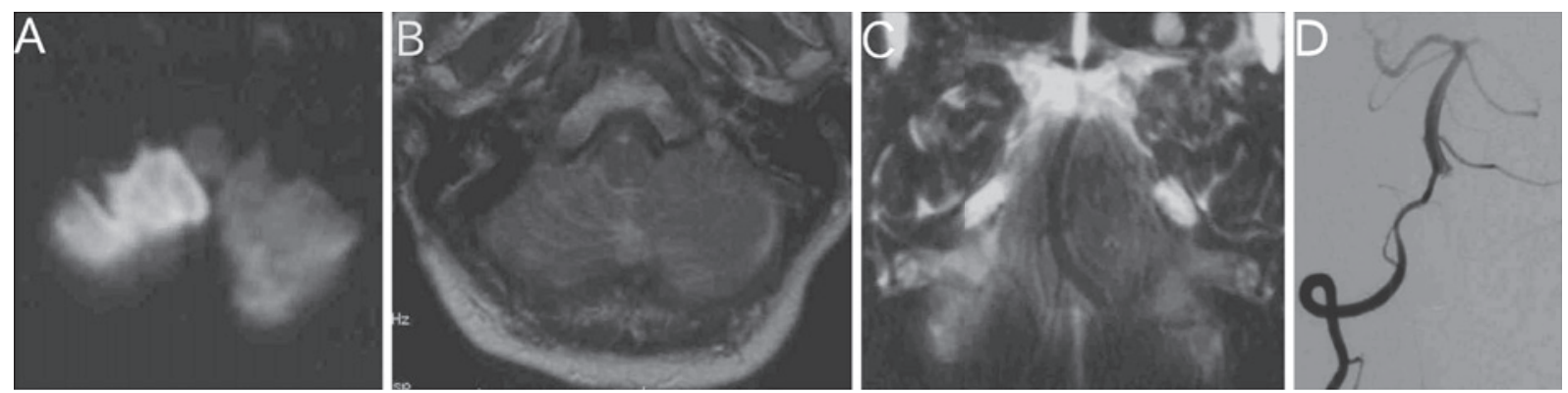

Fig. 3 Case 17. A 72-year-old man with headache and diplopia. Although the initial diagnosis, based both on the findings of T2-weighted imaging and angiography and findings on the findings of T2-weighted imaging and basiparallel anatomical scanning (BPAS), was atherothrombosis, the final diagnosis was dissection because a small mural hematoma was detected on follow-up magnetic resonance imaging. (A) Acute cerebral infarction at the right cerebellar hemisphere was observed on diffusion-weighted imaging. (B) (C) (D) There were no abnormal findings on T2-weighted imaging, BPAS or angiography.

\section{Discussion}

In the acute stage of cerebral infarction determining whether the infarct is due to vertebrobasilar artery dissection or atherothrombosis is difficult. Conventional angiography, which has been the standard diagnostic technique for diagnosing dissection ${ }^{4-8}$, has a risk of complications and does not provide information on the conditions of the arterial wall. Moreover, the angiographic appearance of artery 
occlusion due to dissection is nonspecific because other factors such as thromboembolism or atherosclerotic disease, can produce similar angiographic findings. MRI is an alternative noninvasive approach and the only reliable means for diagnosing occlusive dissection. We have previously reported on 7 patients in whom T2weighted MRI yielded both false-positive results (4 patients) and false-negative results (3 patients). We postulated that the false-negative results with T2weighted MRI were attributable to the fact that in the presence of arterial dissection, the signal intensity of intramural hematomas on T1- and T2weighted MRI depends on the stage of the hemorrhage. The isointense $\mathrm{T} 1$ signal and the increased T2 signal appear after a few hours of bleeding (oxyhemoglobin phase), the T2 signal becomes hypointense in the acute stage (deoxyhemoglobin phase), and $\mathrm{T} 1$ and $\mathrm{T} 2$ signals become hyperintense in the sub-acute stage (methemoglobin phase) ${ }^{10}$. Therefore, if the patient is examined during the acute stage (deoxyhemoglobin phase), the mural hematoma can appear hypointense, and an overlapping arterial flow void can be present on T2-weighted MRI.

An intimal flap, which is often seen on T2weighted MRI of normal internal carotid arteries, suggesting flow artifacts ${ }^{4}$. The false-positive T2weighted MRI findings in our earlier study showed isointensity- or hyperintensity. Vulnerable plaques such as lipid-rich plaques, and intra-plaque hemorrhages are often seen in patients with cerebral infarction due to artery-to-artery embolism ${ }^{11}$. Lipid-rich plaques are reported hyperintense on T2-weighted MRI, and intra-plaque hemorrhage is isointense ${ }^{12}$. Therefore, we postulate that in cases with false-positive results on $\mathrm{T} 2$ weighted MRI, we were unable to distinguish between mural hematomas and vulnerable plaques.

Using BPAS-MRI we obtained a false-negative result in a patient who initially showed no abnormal findings on neurological imaging. However, because follow-up T1- and T2-weighted MRI revealed a small mural hematoma, we changed the diagnosis from cardiac embolization to artery-to-artery embolization due to dissection.
Although BPAS-MRI, which is essentially a modified form of MR cisternography, cannot detect small lesions, it does allow the unique outer contour of the vertebrobasilar artery within the cistern to be visualized. In this respect, BPAS-MRI differs from established vascular imaging methods, such as angiography and MRA, which reveal the inner vascular contour. In the present study, the final diagnosis in patients whose vessels demonstrated a normal outer appearance on BPAS-MRI scans was atherosclerotic change, despite vessel wall irregularities such as the string sign on conventional angiographs.

A diagnosis of vascular dissection is usually based on the combination of clinical symptoms and the findings of MRI and conventional angiography. We found that the specificity of BPAS-MRI or angiography was higher with T2-weighted MRI than without and that the diagnostic accuracy rate of T2weighted MRI was higher with BPAS-MRI than with angiography. However, even the diagnosis of dissection established with BPAS and T2-weighted MRI findings is not always accurate because the sensitivity and specificity of this combination in the present study was not $100 \%$. On the basis of the present results, we recommend more careful studies to determine the presence of dissection.

\section{Conclusion}

Our results suggest that to accurately diagnose of dissection, both the inner and outer contours of the vessels must be considered and that BPAS-MRI might be used instead of conventional angiography to rule out dissection in patients with cerebral infarction.

\section{References}

1. Takumi I, Mizunari T, Mishina M, et al.: Dissecting posterior inferior cerebellar artery aneurysm presenting with subarachnoid hemorrhage right after anticoagulant and antiplatelet therapy against ischemic event. Surg Neurol 2007; 68: 103-107.

2. Fischer CM, Ojemann RG, Roberson GH : Spontaneous dissection of cervico-cerebral arteries. Can J Neurol Sci 1978; 5: 9-19.

3. Hart RG, Easton JD: Dissections of cervical and 
cerebral arteries. Neurol Clin 1983; 1: 155-182.

4. Hosoya T, Adachi M, Yamaguchi K, Haku T, Kayama T, Kato T: Clinical and neuroradiological features of intracranial vertebrobasilar artery dissection. Stroke 1999; 30: 1083-1090.

5. Hosoya T, Watanabe N, Yamaguchi K, Kubota H, Onodera Y: Intracranial vertebral artery dissection in Wallenberg syndrome. Am J Neuroradiol 1994; 15: 1161-1165.

6. Kasner SE, Hankins LL, Bratina P, Morgenstern LB: Magnetic resonance angiography demonstrates vascular healing of carotid and vertebral artery dissections. Stroke 1997; 28: 1993-1997.

7. Kitanaka C, Tanaka J, Kuwahara M, Teraoka A: Magnetic resonance imaging study of intracranial vertebrobasilar artery dissections. Stroke 1994; 25: $571-575$.

8. Levy C, Laissy JP, Raveau V, et al:: Carotid and vertebral artery dissections: three-dimensional timeof-flight MR angiography and MR imaging versus conventional angiography. Radiology 1994; 190: 97103
9. Nagahata M, Abe $\mathrm{Y}$, Ono S, Hosoya $\mathrm{T}$, Uno S: Surface appearance of the vertebrobasilar artery revealed on basiparallel anatomical scanning (BPAS)MR imaging: its role for brain MR examination. Am J Neuroradiol 2005; 26: 2508-2513.

10. Shah GV, Quint DJ, Trobe JD: Magnetic resonance imaging of suspected cervicocranial arterial dissections. J Neuroophthalmol 2004; 24: 315-318.

11. Naghavi M, Libby P, Falk E, et al.: From vulnerable plaque to vulnerable patient: a call for new definitions and risk assessment strategies: Part I. Circulation 2003; 108: 1664-1672.

12. Honda M, Kawahara I, Kitagawa N, et al.: Asymptomatic carotid artery plaques: use of magnetic resonance imaging to characterize vulnerable plaques in 6 cases. Surg Neurol 2007; 67: $35-39$.

(Received, April 29, 2011)

(Accepted, August 3, 2011) 